\title{
Prenatal programming of postnatal obesity: fetal nutrition and the regulation of leptin synthesis and secretion before birth
}

\author{
I. C. McMillen*, B. S. Muhlhausler, J. A. Duffield and B. S. J. Yuen \\ Discipline of Physiology, School of Molecular and Biomedical Sciences, University of Adelaide, \\ Adelaide, SA 5005, Australia
}

\begin{abstract}
Exposure to either an increased or decreased level of intrauterine nutrition can result in an increase in adiposity and in circulating leptin concentrations in later life. In animals such as the sheep and pig in which fat is deposited before birth, leptin is synthesised in fetal adipose tissue and is present in the fetal circulation throughout late gestation. In the sheep a moderate increase or decrease in the level of maternal nutrition does not alter fetal plasma leptin concentrations, but there is evidence that chronic fetal hyperglycaemia and hyperinsulinaemia increase fetal fat mass and leptin synthesis within fetal fat depots. Importantly, there is a positive relationship between the relative mass of the 'unilocular' component of fetal perirenal and interscapular adipose tissue and circulating fetal leptin concentrations in the sheep. Thus, as in the neonate and adult, circulating leptin concentrations may be a signal of fat mass in fetal life. There is also evidence that leptin can act to regulate the lipid storage, leptin synthetic capacity and potential thermogenic functions of fat before birth. Thus, leptin may act as a signal of energy supply and have a 'lipostatic' role before birth. Future studies are clearly required to determine whether the intrauterine and early postnatal nutrient environment programme the endocrine feedback loop between adipose tissue and the central and peripheral neuroendocrine systems that regulate energy balance, resulting in an enhanced risk of obesity in adult life.
\end{abstract}

Leptin: Fetus: Adiposity: Obesity: Fetal Nutrition

\section{High birth weight, fetal nutrition and obesity in later life}

During the past two decades there has been a marked increase in the global prevalence of adult and childhood obesity, and currently $>50 \%$ of all adults in the USA and the UK are overweight, i.e. have a BMI of $>25 \mathrm{~kg} / \mathrm{m}^{2}$ (James, 1996; Campfield et al. 1998; World Health Organization, 1998). In this context it is of particular interest that a range of epidemiological, clinical and experimental studies have shown that there is a relationship between the fetal nutrient environment and patterns of postnatal growth and adult adiposity (O'Brien et al. 1999; Breier et al. 2001). The relationship between birth weight and fatness, measured in childhood or adulthood, is generally positive, although a number of studies have reported that there is a ' $J$ '-shaped or ' $U$ '-shaped relationship between birth weight and adult fat mass, with a higher prevalence of obesity occurring at both low and high birth weights, suggesting a more complex association between growth in utero and obesity (Seidman et al. 1991; Law et al. 1992; Fall et al. 1995; Sorensen et al. 1997).
A recent study in a large British cohort (Parsons et al. 2001) has found a weak but positive relationship between birth weight and BMI at age 33 years, and that this relationship is largely accounted for by maternal weight, i.e. heavier mothers have heavier babies and these babies go on to have a high BMI in adult life. In contrast paternal weight, gestational age, social class, parity, mother's age and mother's smoking habits have no influence on the relationship between birth weight and BMI at 33 years (Parsons et al. 2001). It has been suggested that the influence of maternal weight on the relationship between birth weight and subsequent BMI may operate through an impact of high maternal, and hence fetal, nutrient supply. It has previously been shown that conditions associated with an increase in fetal glucose supply, such as maternal diabetes mellitus, gestational diabetes or even mildly-impaired glucose tolerance during pregnancy, are also risk factors for the development of obesity and glucose intolerance in the offspring (Dorner \& Plagemann, 1994; Buchanan \& Kjos, 1999). In one long-term follow up of infants of diabetic mothers (Silverman et al. 1991) it has been shown that $50 \%$ of newborn infants have weights greater than that for the 
90th percentile for gestational age. After 5 years of age relative weight is increased markedly, and by 8 years of age half the group whose mothers were diabetic in pregnancy have weights greater than that for the 90th percentile. This childhood obesity is correlated with maternal prepregnancy weight and independently with amniotic fluid insulin at 32-38 weeks gestation.

There has been a focus on the role of perinatal hyperinsulinism and the interaction between insulin and leptin in the development of childhood obesity after exposure to in utero hyperglycaemia. Leptin, a polypeptide hormone (approximately $16 \mathrm{kDa}$ ), is synthesised and secreted by adipose tissue and acts as a circulating signal of fat mass through binding to specific receptors at a number of central and peripheral sites to decrease food intake and increase energy utilisation (Friedman \& Halaas, 1998; Jequier \& Tappy, 1999; Ahima \& Flier, 2000; Schwartz et al. 2000). Several studies have reported that leptin concentrations in umbilical cord blood are high in infants who are large for gestational age, and both adiposity and insulin separately contribute to the increased leptin concentrations (Koistinen et al. 1997; Schubring et al. 1997; Shekhawat et al. 1998; Lepercq et al. 1999; Wiznitzer et al. 2000). Interestingly, it has been shown that infants with asymmetric macrosomia with non-diabetic mothers also have high plasma leptin and insulin concentrations. Finally, serum leptin is elevated early in the development of childhood-onset obesity, and obese children have a high serum leptin even when normalised to fat mass (Lahlou et al. 1997).

\section{Low birth weight, fetal nutrition and obesity in later life}

Most studies have shown that individuals who are small babies tend to have a lower weight-for-height (BMI) in adult life than individuals who are larger at birth, although there is also evidence that individuals who are small at birth tend to have a more abdominal distribution of obesity, a markedly reduced muscle mass and a high body fat content in adult life despite their lower BMI (Law et al. 1992). Exposure to a reduced nutrient supply in early pregnancy, as occurred in the Dutch Winter Famine in 1944-5, also results in increased adiposity in later life. In individuals exposed to this famine during early gestation it has been shown that there is an increase in body weight, BMI and waist circumference at 50 years of age (Ravelli et al. 1976). Interestingly, Parsons et al. (2001) have found that those low-birth-weight babies who are most vulnerable to developing obesity are men who were light and thin at birth and experienced a period of rapid childhood growth. Thus, men with a lower birth weight who achieve more adult height by age 7 years have a risk of obesity comparable with that for men with higher birth weights.

Whilst plasma leptin concentrations are low in growthrestricted infants at birth (Jaquet et al. 1998), they increase to become higher in these infants at 1 year of age when compared with their normal-birth-weight counterparts (Jacquet et al. 1999). Moreover, the relationship between serum leptin concentrations and BMI disappears in the growthrestricted cohort during the first year of life (Jacquet et al. 1999). It has also been demonstrated that individuals with low birth weight also go on to have higher leptin concentrations in adult life when compared with individuals at the same BMI but with a higher birth weight (Phillips et al. 1999).

The relationship between poor intrauterine nutrition and altered body composition has also been confirmed in experimental studies in a range of animal models. Lambs with low birth weights are fatter at body weights $\leq 20 \mathrm{~kg}$ when compared with lambs with high birth weights, and this effect is independent of the rate of postnatal growth (Greenwood et al. 1998). In this study the increased fat mass has been attributed to the higher relative voluntary food intake in the low-birth-weight group during the early postnatal period coupled with their relatively lower energy requirements. Furthermore, in rats maternal undernutrition throughout gestation results in offspring that develop obesity, hyperleptinaemia, hyperinsulinism and hypertension during adult life, and postnatal hyperenergetic nutrition amplifies the metabolic abnormalities induced by programming (Vickers et al. 2000). Thus, restricted fetal nutrient supply and poor fetal growth can programme alterations in metabolic capacity beyond the postnatal period and into adult life.

In summary, exposure either to excess or a poor level of nutrition in utero can result in an increase in adiposity and in circulating leptin concentrations in later life. One possibility is that exposure of the fetus to periods of either over- or undernutrition results in perturbations of the development of the endocrine feedback loop between adipose tissue and the central and peripheral control systems that regulate energy balance and body fat mass. The present review summarises the evidence that there is nutrient regulation of leptin synthesis and secretion before birth and that fetal leptin acts at central or peripheral target sites before birth. The possible mechanisms whereby an alteration in nutrient supply during fetal life may act to programme the synthesis, secretion or actions of leptin to result in an increased risk of postnatal obesity will also be discussed.

\section{Leptin and the regulation of energy balance and adiposity in the adult}

In adult mammals circulating leptin concentrations are positively correlated with body fat content and with BMI (Havel et al. 1996; Blache et al. 2000; Thomas et al. 2001). In the adult a central neural network within the hypothalamus integrates signals relating to energy supply, energy stores and energy demand, and leptin acts at central receptors to decrease food intake and to increase fat mobilisation and oxidation (Campfield et al. 1996a,b; Friedman \& Halaas, 1998; Woods et al. 1998; Kalra et al. 1999; Schwartz et al. 2000).

Neuropeptide Y (NPY) is a thirty-six amino acid neuropeptide located in the arcuate nucleus of the hypothalamus with terminals that project to the paraventricular nuclei (PVN). NPY is the most powerful appetite stimulant known and central administration of NPY into the PVN markedly increases feeding activity and can lead to obesity (Friedman \& Halaas, 1998; Woods et al. 1998; Kalra et al. 1999; 
Schwartz et al. 2000). Fasting or food restriction markedly increases NPY expression in the arcuate nuclei and NPY release into the PVN both in vivo and in vitro. NPY expression is also appropriately down regulated by signals of increased energy stores, including leptin and insulin. A long-form variant of the leptin receptor is highly expressed on cell bodies in the hypothalamic arcuate nuclei that synthesise NPY. It has been demonstrated that leptin decreases $N P Y$ gene expression in the hypothalamus, and thus the increase in circulating leptin concentrations during periods of increased food intake results in a corresponding decrease in hypothalamic NPY mRNA and a subsequent fall in energy intake (Woods et al. 1998). There is also evidence that leptin regulates the expression of other hypothalamic neuropeptides implicated in the regulation of energy balance, including $\alpha$-melanocyte-stimulating hormone and its precursor proopiomelanocortin. $\alpha$-Melanocyte-stimulating hormone is synthesised in the arcuate nucleus and acts via the melanocortin- 3 and -4 receptors in the PVN and other hypothalamic regions to suppress food intake (Woods et al. 1998). In rats fasting-induced decreases in proopiomelanocortin mRNA in the arcuate nuclei are prevented by leptin treatment. It has been proposed, therefore, that proopiomelanocortin neurones exert a tonic restraint on feeding through $\alpha$-melanocytestimulating hormone-melanocortin-4 receptor signalling. An increase in circulating leptin, therefore, results in an increase in the expression of proopiomelanocortin mRNA and a decrease in the expression of NPY mRNA, which together act to drive a decrease in food intake via actions at several hypothalamic nuclei, including the PVN, ventromedial and dorsomedial nuclei (Friedman \& Halaas, 1998; Woods et al. 1998; Kalra et al. 1999; Schwartz et al. 2000).

In the adult rodent central leptin administration also decreases the mass of white adipose tissue and the gene expression of leptin within white adipocytes, whilst increasing expression of the uncoupling protein 1 gene in brown adipocytes. Thus, an increase in circulating leptin concentrations causes a shift from fat storage to fat mobilisation and oxidation. These effects occur independently of the leptin-induced changes in food intake and are primarily a consequence of the actions of leptin at its functional receptors in the hypothalamus. Recent studies have shown that in the adult activation of the sympathetic nervous system is required for the effects of leptin on leptin and uncoupling protein gene expression in white and brown adipose tissue respectively (Mizuno et al. 1998; Scarpace \& Matheny, 1998; Commins et al. 1999). Interestingly, it has been demonstrated in the mouse that the $\beta_{3}$-adrenoceptor subtype is required for leptin-mediated regulation of leptin mRNA gene expression in white adipose tissue, but is interchangeable with the $\beta_{1^{-}}$and $\beta_{2}$-adrenoceptor subtypes in mediating the effect of leptin on uncoupling protein 1 mRNA expression in brown adipose tissue (Commins et al. 2000). Whilst the actions of leptin on thermogenesis may be important in species such as the rat, which has marked amounts of brown adipose tissue, this role may be relatively limited in the adult human subject in whom the existence of brown adipocytes remains controversial. However, in man brown adipose tissue is present during fetal and newborn life.
During the past 5 years a series of studies have investigated whether leptin is expressed in adipose tissue before birth, and to what extent leptin synthesis and secretion from adipose tissue can be regulated by changes in the level of maternal, and hence fetal, nutrition.

\section{Leptin synthesis and secretion before birth}

Leptin concentrations in umbilical cord blood are positively correlated with birth weight and with neonatal adiposity, and leptin is synthesised in a range of utero-placental and fetal tissues in a number of species, including the mouse, pig and sheep (Hoggard et al. 1997; Yuen et al. 1999, 2002; Chen et al. 2000; Devaskar et al. 2002; Ehrhardt et al. 2002). It has been reported (Yuen et al. 1999) that leptin mRNA is expressed in the perirenal adipose tissue of the sheep fetus and that there is an increase in the relative abundance of leptin mRNA in fetal adipose tissue with increasing gestational age. It has also been found that there is a positive relationship between leptin mRNA expression in fetal adipose tissue and fetal body weight from as early as $90 \mathrm{~d}$ gestation, and it has been suggested, therefore, that the expression of leptin in fetal adipose tissue may be positively regulated by factors that also regulate fetal body growth, such as insulin or the insulin-like growth factors (Yuen et al. 1999). Interestingly, there is a 15-fold decrease in the slope of the relationship between leptin mRNA expression in fetal perirenal adipose tissue and fetal weight after $125 \mathrm{~d}$ gestation (Yuen et al. 1999). Subsequently, it has been shown that leptin is also expressed in the fetal sheep brain and liver but, in contrast to man, leptin is not expressed in the sheep placenta (Thomas et al. 2001; Ehrhardt et al. 2002). Leptin is present in the circulation of the sheep fetus from as early as $40 \mathrm{~d}$ gestation, which is before the development of visible adipose tissue depots, and fetal plasma leptin may therefore originate from either the maternal circulation or from fetal tissues other than adipose tissue at this early stage of pregnancy (Ehrhardt et al. 2002). The sheep placenta expresses the leptin receptor gene (Thomas et al. 2001), and there is a positive correlation between maternal and fetal plasma leptin concentrations throughout late gestation (Yuen et al. 2002). One possibility is that the placental leptin receptor may mediate the uptake of leptin from the maternal circulation into the fetal circulation. This situation would be similar to the postulated mode of action for the short isoform of the leptin receptor in the choroid plexus epithelium to transport leptin from plasma into the cerebrospinal fluid (Wu Peng et al. 1997). There is evidence in the rat that there is transplacental transfer of leptin from the maternal circulation to the fetal circulation, and that this transfer is increased in late gestation concomitant with an increase in the placental expression of short isoform of leptin receptor protein, which is known to facilitate leptin transport (Smith \& Waddell, 2003). Alternatively, maternal body composition or fatness either at the beginning or during pregnancy may determine the leptin synthetic and secretory capacity of both maternal and fetal adipose tissue. Importantly, there is also a positive relationship between the relative abundance of leptin mRNA in fetal perirenal adipose tissue (which comprises $>80 \%$ of the fetal fat mass) and fetal 


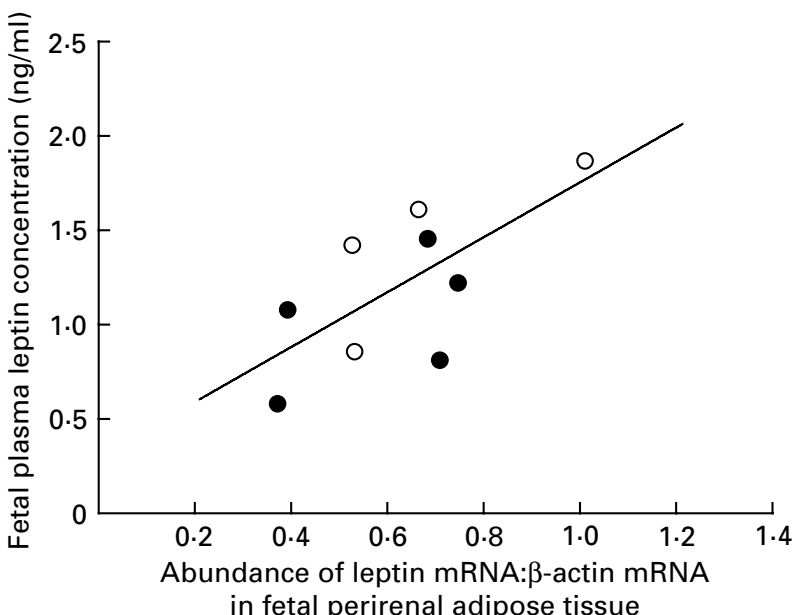

Fig. 1. The relationship between fetal plasma leptin concentrations and the relative abundance of leptin mRNA in fetal perirenal adipose tissue in a group of undernourished $(\mathbf{O})$ and control $(\bigcirc)$ ewes. (Reproduced, with permission, from Yuen et al. 2002.)

plasma leptin concentrations (Yuen et al. 2002), which suggests that fetal adipose tissue is a major source of circulating leptin in the sheep throughout late gestation (Fig. 1). Fetal plasma leptin concentrations are lower than maternal plasma leptin concentrations throughout pregnancy (Ehrhardt et al. 2002; Muhlhausler et al. 2002; Yuen et al. 2002), and whilst an ontogenic rise in plasma leptin has been reported in the relatively hypoleptinaemic fetus of the Welsh Mountain ewe (Forhead et al. 2002), other researchers have not found an increase in plasma leptin concentrations between 115 and $140 \mathrm{~d}$ gestation in fetuses of either Merino (Muhlhausler et al. 2002; Yuen et al. 2002) or Finn $\times$ Dorset pregnant ewes (Ehrhardt et al. 2002).

\section{Maternal nutrition and the regulation of leptin synthesis and secretion in the fetus}

Two studies have investigated the impact of maternal undernutrition on leptin synthesis and secretion in the sheep fetus during late gestation (Ehrhardt et al. 2002; Yuen et al. 2002). Yuen et al. (2002) have reduced maternal feed availability by $50 \%$ for approximately $30 \mathrm{~d}$ and have found that this treatment is associated with a fall in maternal and fetal plasma glucose concentrations. Whilst maternal plasma leptin concentrations are lower in undernourished ewes, there is no effect of maternal undernutrition on the fetal plasma concentrations of leptin or on the relative abundance of leptin mRNA in the fetal perirenal adipose tissue. A second study has found that a similar reduction in maternal nutrition between 122 and $135 \mathrm{~d}$ gestation also reduces maternal plasma leptin concentrations but has no effect on circulating leptin concentrations in the fetus (Ehrhardt et al. 2002). It has recently been shown, however, that periods of fetal hypoglycaemia and hypoinsulinaemia of longer than approximately $36 \mathrm{~d}$ in late gestation result in a suppression of leptin mRNA expression in the perirenal adipose tissue of the sheep fetus (Devaskar et al. 2002).
Together these studies indicate that the synthesis and secretion of leptin in the sheep fetus are relatively resistant to the changes in fetal glucose and insulin concentrations associated with moderate maternal undernutrition. Fetal leptin synthesis is suppressed, however, in the presence of profound fetal hypoglycaemia or hypoinsulinaemia, which may occur as a consequence of either pharmacological induction of maternal hypoglycaemia or severe maternal undernutrition.

When the dietary intake of adolescent pregnant ewes is increased from a moderate to a high plane at $50 \mathrm{~d}$ pregnancy, maternal plasma leptin concentrations increase within $48 \mathrm{~h}$ and circulating leptin concentrations in the ewe are correlated with indices of maternal body composition at 50-90d after the change in diet (Thomas et al. 2001).

It has also been demonstrated that a moderate increase $(55 \%)$ in maternal nutrient intake above maintenance requirements increases maternal plasma glucose and leptin concentrations during late gestation (Muhlhausler et al. 2002). Fetal plasma glucose and insulin concentrations are also increased in well-fed ewes, but there is no concomitant increase in either total fetal fat mass or in fetal plasma leptin concentrations (Muhlhausler et al. 2002). Whilst this nutritionally-induced increase in maternal and fetal plasma glucose and insulin concentrations does not result in an increase in fetal leptin concentrations, infusions of glucose, resulting in chronic fetal hyperglycaemia with hyperinsulinaemia, for a $14-20 \mathrm{~d}$ period in late gestation have been shown to increase fetal fat mass (Alexander \& Bell, 1990) and leptin mRNA abundance in fetal perirenal adipose tissue (Devaskar et al. 2002). Interestingly, leptin mRNA expression in fetal adipose tissue is also selectively increased in response to an experimentally-induced 4-5-fold increase in fetal insulin concentrations with maintained euglycaemia, which suggests that insulin, rather than glucose, may regulate fetal leptin synthesis in fetal adipose tissue (Devaskar et al. 2002).

Ultrastructural studies of adipose tissue in the sheep fetus have demonstrated that fetal adipocytes contain multiple lipid locules and an abundance of mitochondria, characteristic features of thermogenic or brown adipose tissue (Gemmell \& Alexander, 1978). Fetal adipocytes also often contain a larger or more dominant lipid locule and, interestingly, Muhlhausler et al. (2002) have reported that whilst there is no correlation between total fat mass and plasma leptin concentrations in the sheep fetus, there is a positive correlation between the relative mass of the 'unilocular' component of perirenal and interscapular fat and circulating leptin concentrations in a cohort of fetuses in pregnant ewes fed at or above maintenance energy requirements during late gestation (Fig. 2). This finding suggests that there is a relationship between the amount of lipid stored within fetal adipocytes and leptin synthesis and secretion in fetal fat stores and, importantly, that circulating leptin concentrations may be a signal of fat mass in fetal life, as it is in the neonate and adult. Future studies are required to determine to what extent fetal insulin and glucose concentrations each contribute to the regulation of the mass of 'unilocular' fetal fat and to leptin synthesis and secretion during late gestation. 


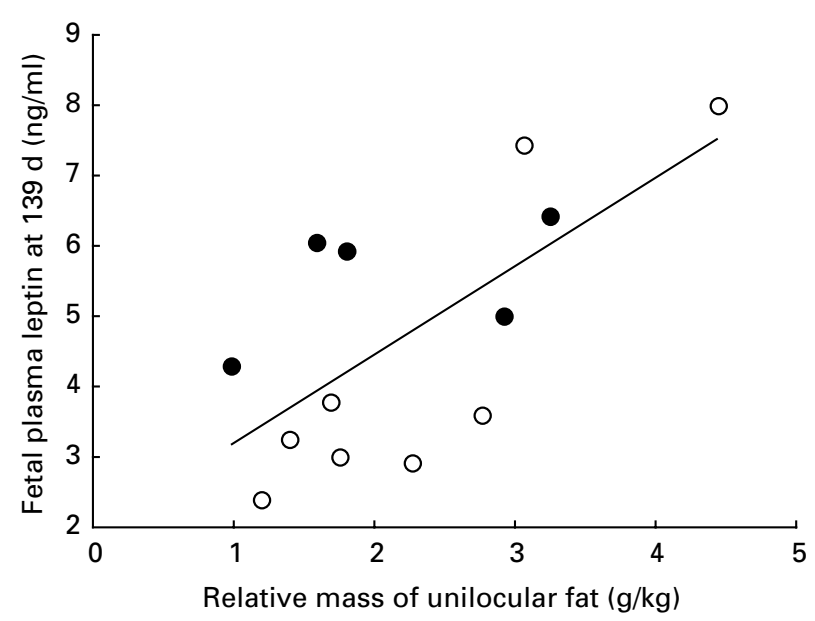

Fig. 2. The relationship between fetal plasma leptin concentrations $(\mathrm{ng} / \mathrm{ml})$ at $139 \mathrm{~d}$ gestation and relative unilocular fat mass $(\mathrm{g} / \mathrm{kg})$ in fetuses of control $(\bullet)$ and well-fed $(\bigcirc)$ ewes. There was a positive correlation between the concentration of leptin $(\mathrm{ng} / \mathrm{ml})$ in the fetal plasma at $139 \mathrm{~d}$ gestation and relative unilocular fat mass $(\mathrm{g} / \mathrm{kg})$. Regression equation: plasma leptin $=1 \cdot 26$ (relative mass of unilocular fat) +1.94 ( $n$ 13, $r 0.68, P<0.02)$. (Reproduced, with permission, from Muhlhausler et al. 2002.)

\section{Actions of leptin before birth}

Whilst there is a correlation between fetal adiposity and circulating leptin concentrations, it is unclear, however, whether leptin plays a role in the control of energy balance before birth. There are obviously key differences between the fetus and adult in the regulation of energy balance. The fetus cannot alter feed intake to maintain nutrient availability and, given the dominant role of the maternal nutrient pool in fetal energy supply, it could be argued that there is little need for an endocrine feedback loop between fetal adipose tissue and the fetal brain to respond to signals of energy supply in the fetus. At birth, however, the fetus moves from a placental to an oral energy supply, and a central neural network that regulates food intake and energy expenditure is immediately required. The effects of leptin administration in the sheep fetus on circulating glucose and insulin concentrations and on the mass and structural characteristics of fetal perirenal adipose tissue have recently been investigated (Yuen et al. 2003). Leptin infusion results in a marked shift in the size distribution of the lipid locules present within the fetal perirenal adipose tissue, with an increase in the proportion of smaller lipid locules. This size shift is associated with an increase in the proportion of multilocular tissue and a decrease in the proportion and relative mass of unilocular tissue in this adipose depot in the leptin-infused fetuses (Fig. 3). The relative abundance of leptin mRNA in perirenal adipose tissue is also lower in leptin-infused fetuses, and there is a direct correlation between leptin mRNA expression and the percentage of unilocular adipose tissue present in the perirenal fat depot in the saline- and leptin-infused groups (Fig. 4). These changes occur in the absence of any changes in fetal plasma glucose or insulin concentrations or in fetal arterial blood gas status. These findings suggest that leptin may act as a signal of energy supply and have a

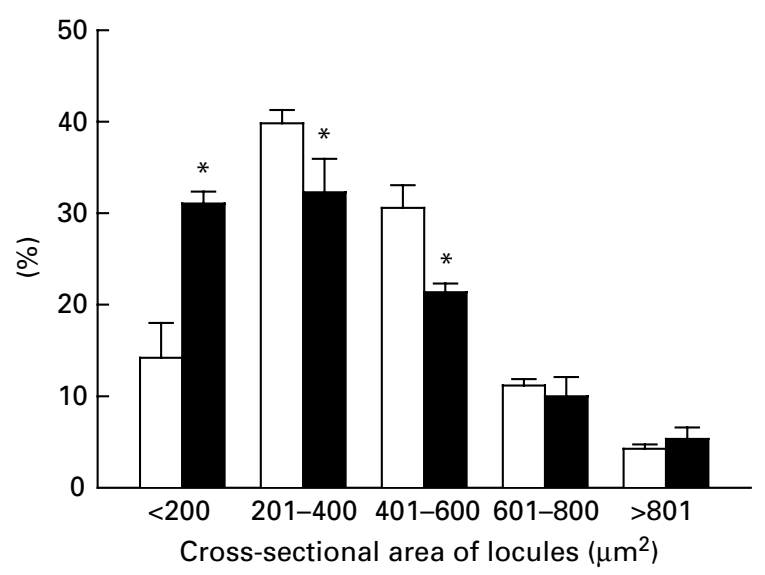

Fig. 3. The proportion of the dominant lipid locules in the perirenal adipose tissue depots in each of the defined size ranges in fetuses infused with saline $(9 \mathrm{~g}$ sodium chloride/l; $\square)$ or leptin $(0.48 \mathrm{mg} / \mathrm{kg}$ per $\mathrm{d}$; $\square$ ). Values are means with their standard errors represented by vertical bars. Mean values were significantly different from those for the leptin-infused group: ${ }^{\star} P<0 \cdot 05$. (Reproduced, with permission, from Yuen et al. 2003.)

'lipostatic' role before birth. This role may be of particular importance when the fetus is exposed to a transplacental increase in substrate supply, such as occurs when maternal nutrient intake is increased or in pregnancies complicated by maternal glucose intolerance and fetal hyperglycaemia.

One possibility is that leptin in the fetal circulation derived either from the maternal circulation (as in the rat in late gestation, or potentially in the sheep in early gestation) or fetal adipose tissue (as in the sheep and man in late gestation) acts centrally via leptin receptors located on NPY - or proopiomelanocortin-containing neurones within the fetal hypothalamus. As in the adult, the central actions of leptin may in turn result in a stimulation of the sympathetic nervous system and a subsequent decrease in the proportion of the unilocular adipose tissue and in the abundance of leptin mRNA in the fetal fat depots. In the fetal sheep hypothalamus NPY-containing cell bodies are present in the infundibular nucleus, which is the homologue of the rodent arcuate nucleus, and there are NPY-containing terminals within the fetal hypothalamic PVN (Warnes et al. 1998). Whilst leptin may act centrally, it is also possible that leptin acts directly via leptin receptors on the unilocular and multilocular adipocytes to stimulate lipolysis and the shift in the distribution of the lipid locule sizes.

\section{Leptin and the prenatal programming of postnatal obesity}

The evidence summarised earlier indicates that leptin is synthesised in fetal adipose tissue and that there is a relationship between relative unilocular fat mass and circulating leptin concentrations in the fetus during late gestation. Appetite-regulating neuropeptides are expressed in the fetal brain and their expression can be altered by changes in maternal nutrition. In addition, intrafetal administration of leptin results in changes in the lipid storage, leptin synthetic capacity and potential thermogenic functions of fat before 


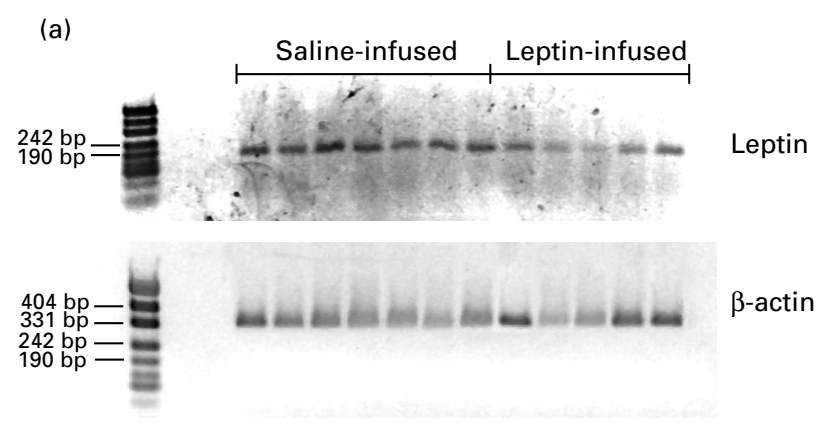

(b)

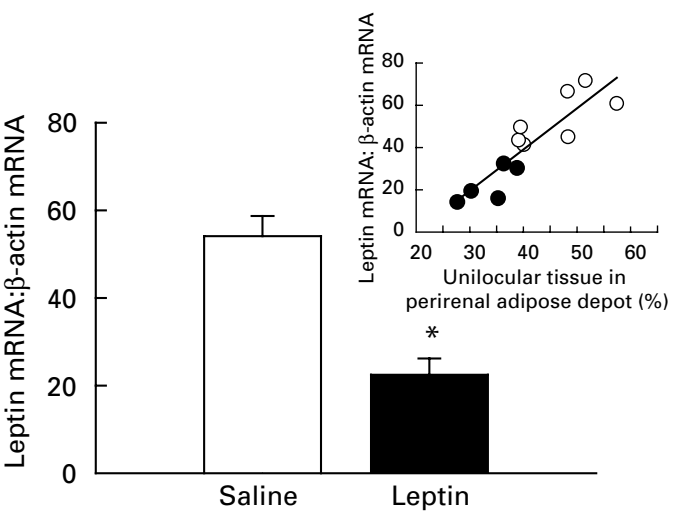

Fig. 4. (a) Leptin (183bp) and $\beta$-actin (349bp) RT-PCR products were amplified from total RNA extracted from the perirenal adipose tissue of saline $(9 \mathrm{~g}$ sodium chloride/l)- and leptin $(0.48 \mathrm{mg} / \mathrm{kg}$ per d)-infused fetal sheep. Products underwent electrophoresis through an ethidium bromide-stained agarose gel. Molecular markers also underwent electrophoresis in the same gel. (b) The relative abundance of leptin mRNA in perirenal adipose tissue from leptin-infused and saline-infused fetuses. Values are means with their standard errors represented by vertical bars. Mean value was significantly different from that for the saline-infused group: ${ }^{*} P<0.05$. The inset plot shows the relationship between the proportion of unilocular tissue and the relative abundance of leptin mRNA in the same adipose depot. Regression equation: leptin mRNA: $\beta$-actin mRNA 1.94 (\% unilocular tissue) - 38.7 (r 0.88, $P<0.0001)$. (Reproduced, with permission, from Yuen et al. 2003.)

birth. It is unclear, however, to what extent exposure to either relative hypo- or hyperleptinaemia in utero may result in programming of the central or peripheral energyregulating systems in postnatal life to result in an increase in an energy intake and/or a decrease in energy expenditure and risk of postnatal obesity. It has been demonstrated that maternal undernutrition results in an increase in NPY mRNA expression in the fetal sheep hypothalamus, although it is unclear whether it is alterations in fetal plasma leptin, insulin or glucose concentrations that regulate hypothalamic NPY expression in the fetus (Warnes et al. 1998). In newborn rats the induction of undernutrition by increasing litter size results in an increase in NPY concentrations in the arcuate nucleus and PVN (Rajakumar et al. 1998), and this change may underlie the programming of hyperphagia that occurs after exposure to a period of maternal undernutrition (Greenwood et al. 1998; Vickers et al. 2000). It has also been demonstrated that the maximum food intake levels during the first 2 weeks after birth of lambs that weighed $2-3 \mathrm{~kg}$ at birth are approximately $50 \mathrm{~g} / \mathrm{kg}$ per day higher than those of lambs that weighed $4-6 \mathrm{~kg}$ at birth (Greenwood et al. 1998).

Future studies are clearly required to determine whether the impact of the intrauterine and early postnatal nutrient environment on leptin synthesis, secretion and action underlie a reprogramming of the endocrine feedback loop between adipose tissue and the central and peripheral neuroendocrine systems that regulate energy balance to result in an increase in body fat mass in adult life. In light of the increase in the prevalence of the 'heavy' mother in developed countries and the increasing prevalence of the combination of low maternal weight, low birth weight and rapid postnatal weight gain in developing countries, such studies may be of critical importance in identifying those critical windows during development and early childhood when intervention may be effective in breaking the intergenerational cycle that leads to adult obesity and its associated comorbidities.

\section{References}

Ahima RS \& Flier JS (2000) Leptin. Annual Reviews in Physiology 62, 413-437.

Alexander GR (1978) Quantitative development of adipose tissue in foetal sheep. Quarterly Australian Journal of Biological Sciences 31, 489-503.

Alexander GR \& Bell AW (1990) Effect of prolonged glucose infusion into fetal sheep on body growth, fat deposition and gestation length. Journal of Developmental Physiology 13, 277-281.

Blache D, Tellam RL, Chagas LM, Blackberry MA, Vercoe PE \& Martin GB (2000) Level of nutrition affects leptin concentrations in plasma and cerebrospinal fluid in sheep. Journal of Endocrinology 165, 625-637.

Breier BH, Vickers MH, Ikenasio BA, Chan KY \& Wong WPS (2001) Fetal programming of appetite and obesity. Molecular and Cellular Endocrinology 185, 73-79.

Buchanan TA \& Kjos SL (1999) Gestational diabetes: risk or myth? Journal of Clinical Endocrinology and Metabolism $\mathbf{8 4}$ 1854-1857.

Campfield LA, Smith FJ \& Burn B (1998) Strategies and potential molecular targets for obesity treatment. Science 280, 1383-1387.

Campfield LA, Smith FJ \& Burn P (1996a) The OB protein (leptin) pathway - a link between adipose tissue mass and central neural pathway. Hormone and Metabolism Research 28, 619-632.

Campfield LA, Smith FJ, Devos R, Burn P \& Guisez Y (1996b) $\mathrm{Ob}$ protein: a peripheral signal linking adiposity and central neural networks. Appetite 26, 302-306.

Chen X, Lin J, Hausman DB, Martin RJ, Dean RG \& Hausman GJ (2000) Alterations in fetal adipose tissue leptin expression correlate with the development of adipose tissue. Biology of the Neonate 78, 41-47.

Commins SP, Marsh DJ, Thomas SA, Watson PM, Padgett MA Palmiter R \& Gettys TW (1999) Norepinephrine is required for leptin effects on gene expression in brown and white adipose tissue. Endocrinology 140, 4772-4778.

Commins SP, Watson PM, Levin N, Beiler RJ \& Gettys TW (2000) Central leptin regulates the UCP1 and ob genes in brown and white adipose tissue via different beta-adrenoceptor subtypes. Journal of Biological Chemistry 275, 33059-33067. 
Devaskar SU, Anthony R \& Hay W (2002) Ontogeny and insulin regulation of fetal ovine white adipose tissue leptin expression. American Journal of Physiology 282, R431-R438.

Dorner G \& Plagemann A (1994) Perinatal hyperinsulinism as possible predisposing factor for diabetes mellitus, obesity and enhanced cardiovascular risk in later life. Hormone and Metabolism Research 26, 213-221.

Ehrhardt RA, Bell AW \& Boisclair YR (2002) Spatial and developmental regulation of leptin in fetal sheep. American Journal of Physiology 282, R1628-R1635.

Fall CH, Osmond C, Barker DJ, Clark PM, Hales CN \& Stirling Y (1995) Fetal and infant growth and cardiovascular risk factors in women. British Medical Journal 310, 428-432.

Forhead AJ, Thomas L, Crabtree J, Hoggard N, Gardner DS, Giussani DA \& Fowden AL (2002) Plasma leptin concentration in fetal sheep during late gestation: ontogeny and effect of glucocorticoids. Endocrinology 143, 1166-1173.

Friedman JM \& Halaas JL (1998) Leptin and the regulation of body weight in mammals. Nature 395, 763-770.

Gemmell RT \& Alexander GR (1978) Ultrastructural development of adipose tissue in foetal sheep. Quarterly Australian Journal of Biological Sciences 31, 505-515.

Greenwood PL, Hunt AS, Hermanson JW \& Bell AW (1998) Effects of birth weight and postnatal nutrition on neonatal sheep: I. Body growth and composition and some aspects of energetic efficiency. Journal of Animal Science 76, 23542367.

Havel PJ, Kasim-Karakas S, Mueller W, Johnson PR, Gingerich RL \& Stern JS (1996) Relationship of plasma leptin to plasma insulin and adiposity in normal weight and overweight women: effect of dietary fat content and sustained weight loss. Journal of Clinical Endocrinology and Metabolism 81, 4406-4413.

Hoggard N, Hunter L, Duncan JS, Williams LM, Trayhurn P \& Mercer JG (1997) Leptin and leptin receptor mRNA and protein expression in the murine fetus and placenta. Proceedings of the National Academy of Sciences USA 94, 11073-11078.

James WPT (1996) The epidemiology of obesity. In The Origins and Consequences of Obesity, pp. 1-16. [DJ Chadwick and G Cardew, editors]. Chichester, West Sussex: Wiley.

Jaquet D, Leger J, Levy-Marchal C, Oury JF \& Czernichow P (1998) Ontogeny of leptin in human fetuses and newborns: effect of intrauterine growth retardation on serum leptin concentrations. Journal of Clinical Endocrinology and Metabolism 83, 1243-1246.

Jaquet D, Leger J \& Tabone MD (1999) High serum leptin concentrations during catch up growth of children born with intrauterine growth retardation. Journal of Clinical Endocrinology and Metabolism 84, 1949-1953.

Jequier E \& Tappy L (1999) Regulation of body weight in humans. Physiological Reviews 79, 451-485.

Kalra SP, Dube MG, Pu S, Xu B, Horvath TL \& Kalra PS (1999) Interacting appetite-regulating pathways in the hypothalamic regulation of body weight. Endocrine Reviews 20, 68-100.

Koistinen HA, Koivisto VA, Andersson S, Karonen SL, Kontula K, Oksanen L \& Teramo KA (1997) Leptin concentration in cord blood correlates with intrauterine growth. Journal of Clinical Endocrinology and Metabolism 82, 3328-3330.

Lahlou N, Landais P, De Boissieu D \& Bougneres PF (1997) Circulating leptin in normal children and during the dynamic phase of juvenile obesity: relation to body fatness, energy metabolism, caloric intake, and sexual dimorphism. Diabetes 46, 989-983.

Law CM, Barker DJ, Osmond C, Fall CH \& Simmonds SJ (1992) Early growth and abdominal fatness in adult life. Journal of Epidemiology and Community Health 46, 184-186.

Lepercq J, Lahlou N, Timsit J, Girard J \& Mouzon SH (1999) Macrosomia revisited: ponderal index and leptin delineate subtypes of fetal overgrowth. American Journal of Obstetrics and Gynaecology 181, 621-625.

Mizuno, A, Murakami T, Otani S, Kuwajima M \& Shima K (1998) Leptin affects pancreatic endocrine functions through the sympathetic nervous system. Endocrinology 139, 3863 3870 .

Muhlhausler BS, Roberts CT, McFarlane JR, Kauter KG \& McMillen IC (2002) Fetal leptin is a signal of fat mass independent of maternal nutrition in ewes fed at or above maintenance energy requirements. Biology of Reproduction 67, 493-499.

O'Brien PM, Wheeler T \& Barker DJ (1999) Fetal Programming: Influences on Development and Disease in Later Life. London: Royal College of Obstetrics and Gynaecology Press.

Parsons TJ, Power C \& Manor O (2001) Fetal and early life growth and body mass index from birth to early adulthood in 1958 British cohort: longitudinal study. British Medical Journal 323, 1331-1335.

Phillips DW, Fall CHD, Cooper C, Norman RJ \& Owens PC (1999) Size at birth and plasma leptin concentrations in adult life. International Journal of Obesity 23, 1025-1029.

Rajakumar PA, He J, Simmons RA \& Devaskar SU (1998) Effect of uteroplacental insufficiency upon brain neuropeptide $\mathrm{Y}$ and corticotrophin releasing factor gene expression and concentrations. Pediatric Research 44, 168-174.

Ravelli GP, Stein ZA \& Susser MW (1976) Obesity in young men after famine exposure in utero and early infancy. New England Journal of Medicine 295, 349-354.

Scarpace PJ \& Matheny M (1998) Leptin induction of UCP1 gene expression is dependent on sympathetic innervation. American Journal of Physiology 275, E259-E264.

Schubring C, Kiess W, Englaro P, Rascher W, Dotsch J, Hanitsch S, Attanasio A \& Blum WF (1997) Levels of leptin in maternal serum, amniotic fluid, and arterial and venous cord blood: relation to neonatal and placental weight. Journal of Endocrinology and Metabolism 82, 1480-1483.

Schwartz MW, Woods SC, Porte D, Seeley RJ \& Baskin DG (2000) Central nervous system control of food intake. Nature 404, 661-671.

Seidman DS, Laor A, Gale R, Stevenson DK \& Danon YL (1991) A longitudinal study of birth weight and being overweight in late adolescence. American Journal of Diseases in Childhood 145, 782-785.

Shekhawat PS, Garland JS, Shivpuri C, Mick GJ, Sasidharin P, Pelz CJ \& McCormick KL (1998) Neonatal cord blood leptin: its relationship to body weight, body mass index, maternal diabetes and steroids. Pediatric Research 43, 338-343.

Silverman BL, Rizzo T, Green OC, Cho NH, Winter RJ, Ogata ES, Richards GE \& Metzger BE (1991) Long-term prospective evaluation of offspring of diabetic mothers. Diabetes 40 , $121-125$.

Smith JT \& Waddell BJ (2003) Leptin distribution and metabolism in the pregnant rat: transplacental leptin passage increases in late gestation but is reduced by excess glucocorticoids. Endocrinology 144, 3024-3030.

Sorensen HT, Sabroe S, Rothman KJ, Gillman M, Fischer P \& Sorensen TI (1997) Relation between weight and length at birth and body mass index in young adulthood: cohort study. British Medical Journal 315, 1137.

Thomas L, Wallace JM, Aitken RP, Mercer JG, Trayhurn P \& Hoggard N (2001) Circulating leptin during ovine pregnancy in relation to maternal nutrition, body composition and pregnancy outcome. Journal of Endocrinology 169, 465-476.

Vickers MH, Breier BH, Cutfield WS, Hofman PL \& Gluckman PD (2000) Fetal origins of hyperphagia, obesity and hypertension and its postnatal amplification by hypercaloric nutrition. American Journal of Physiology 279, E83-E87. 
Warnes KE, Morris MS, Symonds ME, Phillips ID, Clarke IJ, Owens JA \& McMillen IC (1998) Effects of increasing gestation, cortisol and maternal undernutrition on hypothalamic neuropeptide $\mathrm{Y}$ expression in the sheep fetus. Journal of Neuroendocrinology 10, 51-57.

Wiznitzer A, Furman B, Zulili I, Shany S, Reece EA \& Mazor M (2000) Cord leptin level and fetal macrosomia. Obstetrics and Gynaecology 96, 707-713.

Woods SC, Seeley RJ, Porte D \& Schwartz MW (1998) Signals that regulate food intake and energy homeostasis. Science 280, 1378-1383.

World Health Organization (1998) Obesity: Preventing and Managing the Global Epidemic. Geneva: WHO.

Wu-Peng XS, Chua SC Jr, Okada N, Liu SM, Nicolson M \& Leibel RL (1997) Phenotype of the obese Koletsky (f) rat due to Tyr763Stop mutation in the extracellular domain of the leptin receptor (Lepr): evidence for deficient plasma-to-CSF transport of leptin in both the Zucker and Koletsky obese rat. Diabetes 46, 513-518.

Yuen BSJ, McMillen IC, Symonds ME \& Owens PC (1999) Abundance of leptin RNA in fetal adipose tissue is related to fetal body weight. Journal of Endocrinology 163, R1-R4.

Yuen BSJ, Owens PC, McFarlane JR, Symonds ME, Kauter K, Edwards LJ \& McMillen IC (2002) Circulating leptin concentrations are positively related to leptin messenger RNA expression in the adipose tissue of fetal sheep in the pregnant ewe fed at or below maintenance energy requirements during late gestation. Biology of Reproduction 67, 911-916.

Yuen BSJ, Owens PC, Muhlhausler BS, Roberts CT, Symonds ME, Keisler DH, McFarlane JR, Kauter KG, Evens Y \& McMillen IC (2003) Leptin alters the structural and functional characteristics of adipose tissue before birth. FASEB Journal 17, 1102-1104 